\title{
Feedback environment and well-being at work: The mediating role of personal control and feelings of helplessness
}

\author{
Jennifer L. Sparr and Sabine Sonnentag \\ University of Konstanz, Konstanz, Germany
}

\begin{abstract}
This study examines employees' personal control and feelings of helplessness at work as partial mediators of the relationship between the supervisoremployee feedback environment and well-being (job satisfaction, job depression, job anxiety, turnover intentions) at work. Findings are reported from a cross-sectional field study with 345 participants from three different industries. Hierarchical regression analyses showed that feedback environment was positively related to job satisfaction, personal control over information and decisions, and was negatively related to helplessness, job depression, and turnover intentions. Furthermore, personal control partially mediated the relationships between feedback environment and job satisfaction as well as job depression. Helplessness partially mediated the relationships between feedback environment and job depression, job satisfaction, and turnover intentions. This study adds to the literature on feedback environment in highlighting the importance of the supervisor-employee feedback environment for well-being at work and introducing personal control and helplessness as mediating variables.
\end{abstract}

Keywords: Feedback environment; Well-being; Personal control; Helplessness; Job satisfaction; Turnover intentions; Job-related affect.

Prior research about employee reactions to performance feedback and subsequent motivation, performance, and affect at work (e.g., Ashford,

Correspondence should be addressed to Jennifer L. Sparr, Department of Psychology, University of Konstanz, Postbox D42, D-78457 Konstanz, Germany.

E-mail: jennifer.sparr@uni-konstanz.de

This study is part of a larger research project founded by the VolkswagenStiftung. This grant is gratefully acknowledged. We would like to thank Katharina Burde, Henrike Schneider, and Katharina Weitekamp for their support in data collection and Eva J. Mojza and Cornelia Niessen for their helpful comments on earlier drafts of this article. 
1986; Ashford \& Cummings, 1983; Fedor, 1991; Greller \& Herold, 1975; Hackman \& Oldham, 1976; Kinicki, Prussia, Wu, \& McKee-Ryan, 2004; Kluger \& DeNisi, 1996; van den Berg \& Feij, 2003) has shown that performance feedback is an important resource at work (Ashford \& Cummings, 1983). Nevertheless, the relationships between performance feedback and subsequent performance (for a meta-analysis see Kluger \& DeNisi, 1996), well-being at work, and the decision to quit a dissatisfying job (e.g., Walsh, Ashford, \& Hill, 1985) are rather inconsistent. Several authors have pointed out that in order to learn about why and how people react to feedback it might not be enough to focus on isolated feedback events, but that it is necessary to examine the context in which feedback takes place (e.g., Anseel \& Lievens, 2007; Becker \& Klimoski, 1989; Herold \& Parsons, 1985; Levy \& Williams, 2004). This context has been called feedback environment and was first described as workers' perceptions about the availability of specific performance information in their work environment (Herold \& Parsons, 1985). Later, the term feedback environment was used to describe work environments that are supportive for feedback interactions and feedback processes in organizations and it thereby referred to contextual aspects of the feedback process (Levy \& Williams, 2004; Steelman, Levy, \& Snell, 2004).

The interplay of these contextual aspects referring to the feedback message, feedback presentation, and feedback reception in daily work communication (Norris-Watts \& Levy, 2004) is likely to affect work-related outcomes in a more complex way as it could be captured by solely focusing on feedback frequency and feedback sign (positive feedback vs. negative feedback). Therefore, taking into account the feedback environment promises to give new insights into the relationship between feedback and important work-related outcomes. Additionally, an enhanced understanding of the complexity of how employees perceive feedback in the work context might be of high practical relevance for instructing leaders about how to constructively give feedback and how to encourage feedback seeking of their employees in order to enhance job performance and well-being at work.

The purpose of our study was twofold: First, we aimed at replicating earlier findings on the relationship between feedback environment and job satisfaction (Anseel \& Lievens, 2007; Rosen, Levy, \& Hall, 2006) and at extending this research to additional indicators of well-being. Specifically, well-being at work or "job-specific well-being" has been defined as "people's feelings about themselves in relation to their job" (Warr, 1999, p. 393). Warr (1999) conceptualized job-related well-being around three axes: displeasure pleasure, with the positive pole being satisfaction, anxiety comfort, and depression enthusiasm. We chose job anxiety, job depression, and job satisfaction to represent one pole of each dimension. Furthermore, we assessed turnover intentions as a behavioural indicator for well-being at 
work because turnover intentions frequently were shown to be related to well-being at work (George \& Jones, 1996; Griffeth, Hom, \& Gaertner, 2000; Warr, 1999).

Second, we examined the role of personal control and helplessness as partial mediators in the relationship between the feedback environment and well-being at work (see Figure 1 for our conceptual model). Thereby, we intended to extend the existing knowledge about the feedback environment in proposing an important mechanism through which the feedback environment establishes a positive relationship with well-being at work.

\section{THE FEEDBACK ENVIRONMENT}

Steelman et al. (2004, p. 166) described the feedback environment as "the contextual or situational characteristics of the feedback process. The feedback environment refers to the contextual aspects of day-to-day supervisor-subordinate and coworker-coworker feedback processes." Two sources providing the feedback environment of employees are distinguished, namely supervisors and co-workers (Steelman et al., 2004). For both of these sources the feedback environment captures important facets that have been derived from the literature as being relevant to feedback processes, namely source credibility, feedback quality, feedback delivery, favourable and unfavourable feedback, source availability, and promotion of feedback seeking. Source credibility refers to the perceived expertise and trustworthiness of the feedback source, thus capturing the recipient's trust in the ability and motivation of the source to provide accurate feedback. Feedback quality is characterized by the perceived consistency and usefulness of the feedback, thus concerning the informational value of the feedback message. Feedback delivery embraces the perception of the source's intention and consideration in feedback delivery. Favourable and unfavourable feedback

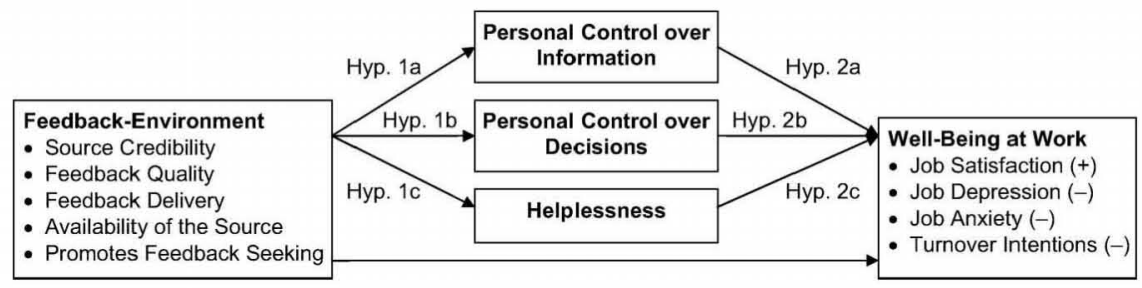

Figure 1. Conceptual model examined in the study. Partial mediation between feedback environment and well-being at work via personal control over information is hypothesized in Hypotheses $3 \mathrm{a}$, via personal control over decisions is hypothesized in Hypothesis $3 \mathrm{~b}$, and via helplessness is hypothesized in Hypothesis $3 \mathrm{c}$. Signs in parentheses indicate the direction of the postulated relationships. 
refers to the recipient's perception of being provided with positive respectively negative feedback when he or she believes that his or her performance warrants this kind of feedback. Source availability describes the perceived amount of contact an employee has to the source of feedback and the possibilities to approach the source in order to obtain feedback. Finally, promotion of feedback seeking refers to the extent the source encourages, supports, and rewards actively asking for feedback by the recipient.

Steelman et al.'s (2004) conceptualization of the feedback environment has been examined in a series of studies, connecting the feedback environment to a variety of work-related outcome variables, including satisfaction with feedback, motivation to use feedback, feedback-seeking frequency, and leader member exchange (LMX) (Steelman et al., 2004), organizational citizenship behaviour mediated by affective commitment (Norris-Watts \& Levy, 2004), managers' accountability of using upward feedback and self-development initiative (Rutkowski \& Steelman, 2005), perceptions of politics, job satisfaction, affective commitment, and performance (Rosen et al., 2006), and job satisfaction mediated by LMX (Anseel \& Lievens, 2007).

In the present study, we chose to focus on the supervisor as source of feedback, similarly to earlier studies (Anseel \& Lievens, 2007; Norris-Watts \& Levy, 2004). A first effective attempt to improve the feedback environment could be to integrate knowledge about the feedback environment into leadership trainings. On the one hand, supervisors learning beneficial ways how to provide high quality feedback and how to encourage feedback seeking probably shape a positive feedback environment for and with their subordinates. On the other hand, trained supervisors can serve as role models for their subordinates by demonstrating how to deal with feedback constructively and thus, spreading the positive consequences also to the co-worker part of the feedback environment because employees might adopt positive feedback-related behaviours from their supervisors.

We decided to focus on five out of the seven feedback environment facets, leaving out favourable and unfavourable feedback. Instead, we control for frequency of plain negative and positive feedback in our analyses. This decision was based on two reasons. First, this procedure gives us the opportunity to study qualitative aspects of the feedback environment separately from feedback quantity and additionally examine the relationships between the feedback environment and frequency of feedback. Second, although we acknowledge the importance of the perceived frequency of positive and negative feedback when it is warranted by the recipient's performance, we are concerned about integrating favourable and unfavourable feedback into the overall feedback environment concept as unfavourable feedback had substantially lower relationships to the outcomes 
examined by Steelman et al. (2004) than the other facets. In addition, the favourable feedback scale contains items not reflecting feedback warranted by performance but purely frequency of positive feedback. Based on these considerations we chose to assess plain frequency of feedback in our data and use them as control variables.

\section{FEEDBACK ENVIRONMENT AND WELL-BEING AT WORK}

By definition, an advantageous feedback environment is characterized by a wealth of information that is high in quality, appropriately and benevolently provided or readily available from trustworthy sources. These benevolent characteristics of the feedback environment are likely to provide employees with important information which they need to fulfil their jobs and which they can readily accept because they feel adequately treated by a trustworthy feedback source (cf. Ilgen, Fisher, \& Taylor, 1979). While a good feedback environment has already been shown to relate positively to performance (Norris-Watts \& Levy, 2004; Rosen et al., 2006), we assume that the focused contextual aspects of feedback also influence employee well-being. In an advantageous feedback environment, besides being provided with sufficient and high-quality information the employee is likely to feel appreciated, carefully treated, and supported from the supervisor. Providing feedback adequately has been recognized as an important leadership behaviour enhancing the well-being of subordinates (van Dierendonck, Haynes, Borrill, $\&$ Stride, 2004). Next we argue that an advantageous feedback environment unfolds its benevolent effects on employee well-being by strengthening employees' personal control and reducing feelings of helplessness.

\section{Feedback environment, personal control, and helplessness}

Control is a rather heterogeneously defined construct in psychology (Skinner, 1996). We use the term personal control at work by applying the definition of Peterson (1999, p. 288): "'Personal control' refers to the individual's belief that he or she can behave in ways that maximize good outcomes and/or minimize bad outcomes." In our study, we focused on personal control over two different aspects, namely personal control over information and personal control over decisions at work. In this context, personal control refers to the individual's belief that he or she is able to obtain important information for and about his or her work and that he or she can influence the way work is done and decisions are made within the work context.

In order to gain personal control over a specific aspect of the environment an individual needs to perceive his or her behaviour to be related to desired outcomes (Greenberger \& Strasser, 1986). Therefore, information is needed 
about the relationship between the behaviour and the outcomes. As information is one important predictor of personal control in the work context (Skinner, 1996) and feedback information is a valuable type of information (Ashford \& Cummings, 1983; Ilgen et al., 1979), adequate feedback about one's performance and outcomes at work are crucial for experiencing control (cf. Greenberger \& Strasser, 1986) and for actually making use of one's control possibilities. An advantageous feedback environment as previously characterized provides feedback information that enables employees to learn about others' expectancies and standards concerning their behaviour, to gain an adequate picture of their competences and actual performance, to accurately assess their behaviour efficiency, and to quickly figure out if changes in their behaviour go into the right direction. The promotion of feedback seeking enables employees to safely get feedback information whenever they need it. As this information is necessary to make informed decisions and an advantageous feedback environment is likely to provide this performance information in an optimal way, personal control over decision making is fostered. In summary, we assume that an advantageous feedback environment gives a high degree of personal control over performance-related information to the employee and enhances personal control over decisions.

Helplessness might be considered as the opposite of personal control: "Helplessness is the psychological state that frequently results when events are uncontrollable" (Seligman, 1975, p. 9). In experimental research about learned helplessness, participants typically are exposed to uncontrollable, usually unpleasant situations (e.g., unsolvable tasks). People learn in these situations that they cannot change the situation through their own behaviour. When these people afterwards are exposed to a similar situation that objectively is under their control, they usually stay passive and do not explore their control possibilities (Peterson, Maier, \& Seligman, 1993). In work settings, employees are confronted with situations in which they are uncertain about how to act in order to reach their goals (cf. Ashford \& Cummings, 1983). If this uncertainty cannot be dissolved and ways to reach one's goal remain unclear (e.g., because feedback is not available), feelings of helplessness are likely to occur. Contrarily, a beneficial feedback environment is likely to provide employees with sufficient and useful feedback about their work behaviour and performance and helps to overcome uncertainty, thus avoiding feelings of helplessness. Additionally, being provided with high quality feedback and being encouraged to actively seek feedback when needed is likely to give a feeling to the employee that he or she does not have to deal with the problem on his or her own but has the possibility to get some help if needed. We included helplessness into our study to examine a general lack of control beliefs in addition to our focus specifically about personal control over information and decisions. 
We state the following hypothesis:

Hypothesis 1: The quality of supervisor employee feedback environment is positively related to (a) personal control over information, to (b) personal control over decisions and (c) negatively related to feelings of helplessness at work.

\section{Personal control, feelings of helplessness, and well-being at work}

A wealth of research found personal control to be an important predictor of well-being (cf. Skinner, 1996; Spector, 2002). In a recent literature review, Warr (2007) showed that opportunities for personal control have been positively related to each of the three well-being axes, namely displeasure pleasure, anxiety comfort, and depression enthusiasm. As many of these studies assessed control opportunities in self-report, that is, subjectively, we assume that these results generalize to personal control which is defined as a subjective control believe. Additionally, Spector (2002) points to the importance of personal control for the perceptions of workplace stressors, thus highlighting the role of personal control for employee well-being. On the one side, personal control is beneficial to well-being in itself because the person perceives him- or herself to be able to achieve his or her goals through self-determination. On the other side, when employees perceive control over the work environment, they may manipulate several aspects of their environment which, in turn, might have beneficial effects for their wellbeing (Warr, 2007). Access to work-related and performance-related information is an important basis for successfully fulfilling one's job requirements. Being deprived of this information might lessen the chances of successful working and thus induces worry and stress for the employee. Therefore, personal control over information at work prevents employees experiencing this source of stress and its negative consequences for wellbeing (cf. Spector, 2002). We expect personal control over decisions also to be positively related to well-being at work because this type of control enables employees to shape their work environment and work activities according to their own preferences.

Learned helplessness has been found to be related to feelings of depression, anxiety and physical illness (Peterson et al., 1993; Seligman, 1975). Although feelings of helplessness in work settings might be less severe than feelings of general helplessness in life, they nevertheless are likely to impair well-being. Empirically, helplessness at work has been found to be positively related to work alienation, which is lack of job involvement and organizational identification (Ashforth, 1989), and to be negatively related to work adjustment in newcomers (Ashforth \& Saks, 2000). These findings 
indicate the relevance of helplessness for employees' adaptation and wellbeing in organizations.

We therefore state the following hypothesis:

Hypothesis 2: (a) Personal control over information and (b) personal control over decisions are positively related and (c) feelings of helplessness are negatively related to well-being at work.

\section{Feedback environment, personal control, feelings of helplessness, and well-being}

Finally, we assume that an advantageous feedback environment is positively related to employee well-being at work. An advantageous feedback environment offers several valuable resources to employees, which are likely to establish and thus mediate the hypothesized relationship. We focused on personal control over information and decisions at work (and feelings of helplessness as the opposite of control) as important resources. Of course, personal control is not the only resource that employees gain from an advantageous feedback environment. For example, the finding of Anseel and Lievens (2007) that the feedback environment's relationship with job satisfaction was mediated by LMX quality stresses the importance of other aspects. We therefore assume a positive relationship between feedback environment and well-being at work being partially mediated by personal control over information, personal control over decisions, and helplessness.

We therefore state the following hypothesis:

Hypothesis 3: (a) Personal control over information, (b) personal control over decisions, and (c) feelings of helplessness partially mediate the relationship between the quality of the supervisor employee feedback environment and well-being at work.

\section{METHOD}

\section{Sample and procedure}

Three hundred and forty-five employees from different organizations in Germany participated in this study. On average the participants were 40.47 years old ( $S D=10.11) ; 53.3 \%$ were female. About half of the sample had a university degree or a comparable education $(55.0 \%), 9.4 \%$ had a craftsman's diploma, $33.8 \%$ had completed an apprenticeship, and only $1.8 \%$ indicated to have no formalized professional training. Mean professional experience was 18.27 years $(S D=10.63)$ and mean job tenure 
was 14.31 years $(S D=9.21)$. About one-third of the sample had a supervisory position $(32.8 \%)$ and more than half of the sample worked in teams $(57.2 \%)$. This overall sample consists of subsamples from three different industries, namely (1) public administration $(N=218)$, (2) research and development (R\&D) $(N=96)$, and (3) health care $(N=30)$. One person failed to provide the information about his or her industry.

Organizations belonging to these three industries were contacted by phone and invited for participation in this study introduced as research on "feedback, reactions to feedback, and behaviour at work". When a contact person (e.g., head of personnel department) signalled an interest in participation we e-mailed them information material explaining the aim and procedure of the study. We asked the contact persons to send the information material to their employees and to encourage them to participate. As an incentive for participation we offered feedback about the results of the study. For organizations taking part with 10 or more participants we additionally offered specific feedback about results from this organization's members compared to the results of the whole sample from the respective industry. Participants could sign up individually by e-mail or fax a form. After signing up we sent an e-mail to the participants with the web link to the questionnaire.

A total of 395 persons indicated that they would like to participate in the study via online questionnaire (119 from R\&D, 22 from health care, 254 from public administration organizations). The number of filled-in online questionnaires was 332 , which indicates a response rate of $84.05 \%$. We additionally sent about 65 paper questionnaires to three different hospitals where participants did not have access to the Internet. Thirteen paper questionnaires were returned. The low response rate of the paper questionnaire procedure occurred because contact persons in these hospitals severely overestimated the number of persons willing to participate. In total, 345 persons completed the self-report questionnaire (total response rate: $76.67 \%$ ). Most of these individuals $(62.8 \%$ ) worked in public administration organizations, $28.5 \%$ worked in R\&D, and $8.6 \%$ worked in hospitals. Please note that the following analyses are based on 344 persons because one person had missing values at a mediator variable.

\section{Measures}

All data are based on participants' self-reports. Questionnaires were provided in German. Table 1 displays means, standard deviations, and zero-order correlations between study variables. In all cases where no German version of the scales we used was available, we employed a translation-back-translation procedure to translate the items from English into German language. 
TABLE 1

Means, standard deviations, reliability, and intercorrelations

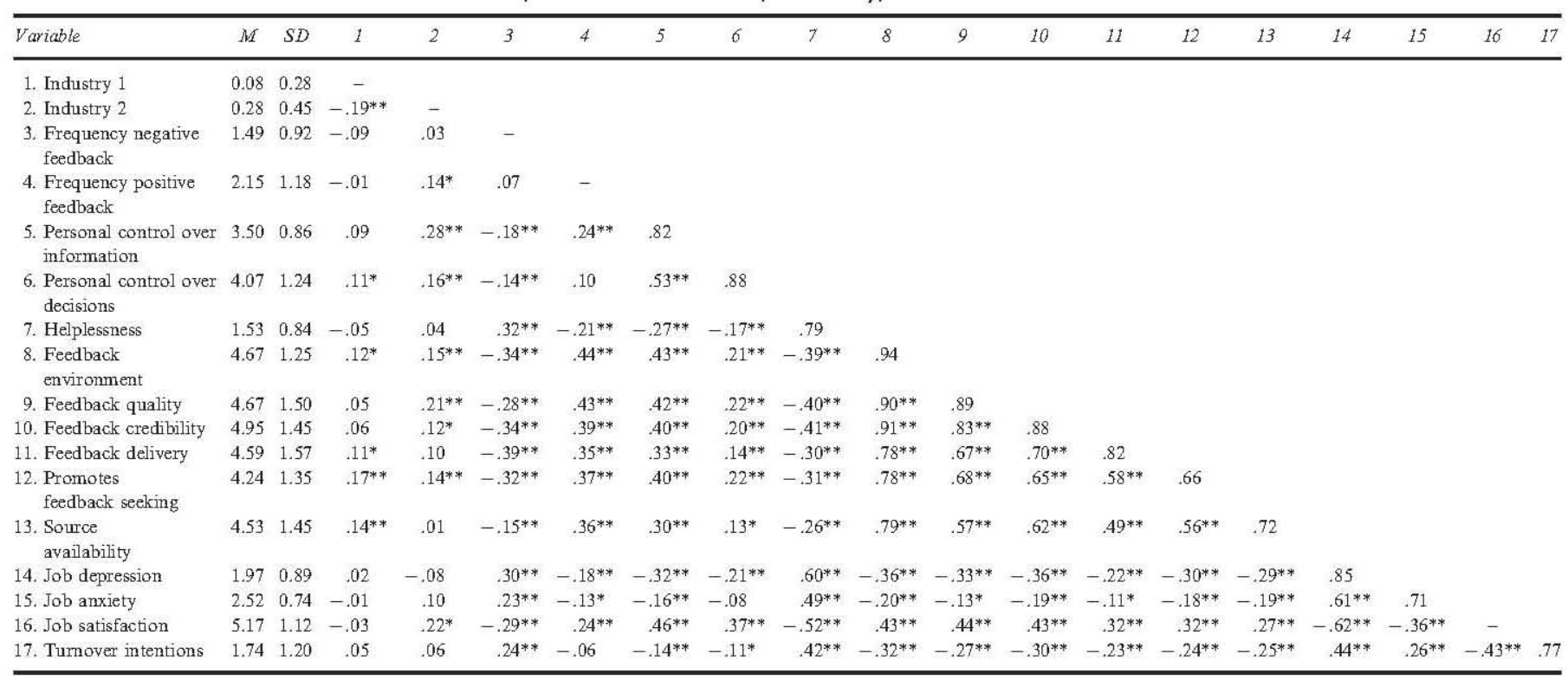

Industry 1 was coded $1=$ hospitals, $0=$ other. Industry 2 was coded $1=R \& D, 0=$ others. Cronbach's alphas appear along the diagonal. ${ }^{*} p<.05$, two-tailed; ** ${ }^{*}<.01$, two-tailed. 
Supervisor employee feedback environment. To assess the supervisor employee feedback environment we used the supervisor part of the feedback environment scale (FES) from Steelman et al. (2004). Specifically, we concentrated on five core facets of the feedback environment as created by the supervisor, namely source credibility ("My supervisor is fair when evaluating my job performance"), feedback quality ("My supervisor gives me useful feedback about my job performance"), feedback delivery ("My supervisor is tactful when giving me performance feedback"), source availability ("My supervisor is usually available when I want performance information"), and promotion of feedback seeking ("I feel comfortable asking my supervisor for feedback about my work performance"). Based on information about item-scale intercorrelations as provided by the reliability analysis we chose the three best fitting items from each facet, resulting in one overall feedback-environment measure with 15 items. Participants answered on a 7-point Likert-type scale ( $1=$ "I strongly disagree", $7=$ "I strongly agree"). Cronbach's alpha was .94. The five single facets were highly correlated and had similar relationships to the mediator variables and outcomes compared to the overall feedback environment measure (see Table 1).

Personal control. We developed three items to measure personal control over information ("How much influence do you have on the informationexchange in your department?", "How much influence do you have on getting important information about your work?", and "How much influence do you have in being well informed about the results of your work?"). Personal control over decisions was measured with a 3-item subscale from Menon's (1991) empowerment questionnaire. One sample item is "I can influence decisions taken in my department." Participants answered on a 5-point Likert-type scale ( 1 = "very little", 5 = "very much") for the information-control scale and on a 6-point Likert-type scale ( $1=$ "I do not agree at all", $6=$ "I do fully agree") for the decision-control scale. Cronbach's alphas were .82 and .88 , respectively. We performed a confirmatory factor analysis to differentiate between these two personal control constructs. Results showed that the two-factor solution had a good fit, $\chi^{2}=17.14, d f=8, p<.05$, RMSEA $=.06$, GFI $=.98, \mathrm{CFI}=.99$, and fitted the data better than a one-factor solution, $\Delta \chi^{2}=269.00, d f=1$, $p<.001$.

Helplessness. We used two items from the helplessness scale of Breitkopf (1985), which can be well applied to the work context. We asked participants how often they have the following thoughts at work: "My situation is completely out of control" and "Even though I struggle, however, there are no results". These questions mirror typical helplessness situations that are 
characterized by lack of control and lack of contingency between one's actions and the outcomes. Participants answered on a 5-point Likert-type scale ( $1=$ "very seldom", 5 = "very often"). Cronbach's alpha was .79.

We performed a confirmatory factor analysis to make sure that the two personal control variables and the helplessness variable represented different constructs. Results showed that the three factor solution had a good fit, $\chi^{2}=36.16, d f=17, p<.01$, RMSEA $=.057, \mathrm{CFI}=.99$, GFI $=.97$, and was significantly better than a one-factor solution, $\Delta \chi^{2}=444.32, d f=3, p<.001$.

Negative affect at work. We measured the dimensions "job depression" and "job anxiety" with the scale of Warr (1990). Sample items were "When you reflect on the last few weeks, how often did you feel depressed at work?", "When you reflect on the last few weeks, how often did you feel tense at work?" Participants answered on a 5-point Likert-type scale $(1=$ "never", $5=$ "always"). Cronbach's alphas were .85 and .71 , respectively. Confirmatory factor analyses showed that the two dimensions of negative affect at work were well distinguishable, $\chi^{2}=23.58, d f=8, p<.01$, RMSEA $=.08, \mathrm{GFI}=.98, \mathrm{CFI}=.99$. The twofactor solution had a significantly better fit than the one-factor solution, $\Delta \chi^{2}=52.65, d f=1, p<.001$.

Job satisfaction. We measured job satisfaction using the faces scale from Kunin (1955) with the answer scale ranging from $1=$ "I am very dissatisfied" to $7=$ "I am extraordinarily satisfied". We used this singleitem measure to assess overall job satisfaction relying on meta-analytic findings, that single-item measures of job satisfaction are highly correlated to scale measures (corrected $R=.67$ for face measures; Wanous, Reichers, \& Hudy, 1997); thus, using a single-item measure is a worthy alternative to less parsimonious scales.

Turnover intentions. We combined three items to assess turnover intentions. These items were namely "I often think on quitting", "I already looked around for another job", and "How likely is it that you will quit your job voluntarily during the next 12 months?" Participants answered the first two items on a 7-point Likert-type scale $(1=$ "does not apply at all", $7=$ "does fully apply") and the third item on a 7-point Likert-type scale ( $1=$ "very unlikely", $7=$ "very likely"). Cronbach's alpha was .77 .

To make sure that our well-being at work measures were distinct constructs, we performed a confirmatory factor analysis to separate job depression, job anxiety, and turnover intentions. This three-factor solution showed good fit to the data, $\chi^{2}=42.19, d f=24, p<.05$, RMSEA $=.05$, $\mathrm{GFI}=.97, \mathrm{CFI}=.99$, and was significantly better than the one-factor solution, $\Delta \chi^{2}=304.63, d f=3, p<.001$. Because helplessness was highly 
correlated to the well-being variables we additionally performed a confirmatory factor analyses to check the distinctness of these constructs. The four-factor solution with job anxiety, job depression, turnover intentions, and helplessness showed good fit to the data, $\chi^{2}=63.54$, $d f=38, p<.01, \mathrm{RMSEA}=.044, \mathrm{GFI}=.97, \mathrm{CFI}=.99$, and was significantly better than the one-factor solution, $\Delta \chi^{2}=391.20, d f=6, p<.001$.

Control variables. As control variables we assessed industry type and frequency of positive and negative feedback from the supervisor. More specifically, we created two dummy variables for the three industry types: Industry Type $1(1=$ health care, $0=$ others $)$, Industry Type $2(1=\mathrm{R} \& \mathrm{D}$, $0=$ others). Including the frequency of supervisor feedback enabled us to examine the qualitative aspects of the feedback environment regardless of the amount of feedback received, which may differ greatly between individuals. Participants answered to the questions "How often did you get negative feedback from your supervisor in the last time?" and "How often did you get positive feedback from your supervisor in the last time?" Answer options ranged from $1=$ "less than once a month" to $7=$ "several times a day".

\section{RESULTS}

We used hierarchical regression analyses to test our hypotheses. In a first step, we entered the control variables, namely the two industry type dummies and frequency of positive and negative feedback from the supervisor, into the regression models. In a second step, we entered feedback environment, respectively the mediator variables, as predictors.

In a first set of models, we tested Hypotheses 1a to 1c, namely the relationships between feedback environment and the mediator variables personal control over information, personal control over decisions, and helplessness. Results are displayed in Table 2. Analysis in the first step showed that both industry types had significant positive relationships with personal control over information and decisions, indicating that employees from hospitals and R\&D reported more personal control than employees from public administration. Frequency of negative feedback from the supervisor was negatively related to personal control over information and personal control over decisions, and positively related to helplessness. Frequency of positive feedback from the supervisor was positively related to personal control over information and negatively related to helplessness. Feedback environment entered in the second step was positively related to personal control over information, explaining an additional $7 \%$ of the variance, and negatively related to helplessness, explaining an additional $4 \%$ of the variance. Feedback environment was only marginally related to 
TABLE 2

Regression results for Hypotheses 1a to 1c

\begin{tabular}{|c|c|c|c|c|c|c|}
\hline & \multicolumn{2}{|c|}{$\begin{array}{c}\text { Personal control } \\
\text { over } \\
\text { information }\end{array}$} & \multicolumn{2}{|c|}{$\begin{array}{l}\text { Personal control } \\
\text { over decisions }\end{array}$} & \multicolumn{2}{|c|}{ Helplessness } \\
\hline & $\beta$ & $t$ & $\beta$ & $t$ & $\beta$ & $t$ \\
\hline \multicolumn{7}{|l|}{ Step 1} \\
\hline Industry 1 & .13 & $2.48^{*}$ & .14 & $2.60^{*}$ & -.03 & -0.55 \\
\hline Industry 2 & .28 & $5.41^{* * *}$ & .18 & $3.33^{* *}$ & -.02 & -0.46 \\
\hline $\begin{array}{l}\text { Frequency negative } \\
\text { feedback from } \\
\text { supervisor }\end{array}$ & -.18 & $-3.66^{* * *}$ & -.14 & $-2.63 * *$ & .32 & $6.40^{* * *}$ \\
\hline \multirow{2}{*}{$\begin{array}{l}\text { Frequency positive } \\
\text { feedback from } \\
\text { supervisor }\end{array}$} & .22 & $4.47^{* * *}$ & .09 & 1.72 & -.24 & $-4.76^{* * *}$ \\
\hline & \multicolumn{2}{|c|}{$R^{2}=.18$} & \multicolumn{2}{|c|}{$R^{2}=.08$} & \multicolumn{2}{|c|}{$R^{2}=.16$} \\
\hline \multicolumn{7}{|l|}{ Step 2} \\
\hline Industry 1 & .09 & 1.77 & .12 & $2.31^{*}$ & .00 & 0.05 \\
\hline Industry 2 & .24 & $4.80^{* * *}$ & .16 & $3.03^{* *}$ & .01 & 0.14 \\
\hline $\begin{array}{l}\text { Frequency negative } \\
\text { feedback from supervisor }\end{array}$ & -.07 & -1.26 & -.09 & -1.65 & .23 & $4.31^{* * *}$ \\
\hline $\begin{array}{l}\text { Frequency positive } \\
\text { feedback from supervisor }\end{array}$ & .07 & 1.26 & .03 & 0.54 & -.12 & $-2.11^{*}$ \\
\hline Feedback environment & \multicolumn{2}{|c|}{$\begin{array}{c}R^{2}=.25 \\
\Delta R^{2}=.07^{* * *}\end{array}$} & \multicolumn{2}{|c|}{$\begin{aligned} R^{2} & =.09 \\
\Delta R^{2} & =.01^{+}\end{aligned}$} & \multicolumn{2}{|c|}{$\begin{array}{c}R^{2}=.20 \\
\Delta R^{2}=.04^{* * *}\end{array}$} \\
\hline
\end{tabular}

Industry 1 was coded $1=$ hospitals, $0=$ other. Industry 2 was coded $1=R \& D, 0=$ others. ${ }^{+} p<.10,{ }^{*} p<.05,{ }^{* *} p<.01,{ }^{* * *} p<.001$.

personal control over decisions. Thus, Hypotheses 1a and 1c received support from the data; Hypothesis $1 \mathrm{~b}$ was marginally supported.

In a second set of models, Hypotheses $2 \mathrm{a}$ to $2 \mathrm{c}$ were tested, in particular the relationships between the mediator variables personal control over information, personal control over decisions, and helplessness with wellbeing consisting of the variables job depression, job anxiety, job satisfaction, and turnover intentions (see Table 3). In the first steps, we again entered the control variables (these steps are identical for testing Hypothesis 2a to 2c and therefore are displayed only once in Table 3, Step 1). Industry type 2 revealed a positive relationship with job anxiety as well as with job satisfaction, indicating that participants from R\&D reported more job anxiety but also more job satisfaction than participants from hospitals or public administration. Frequency of negative feedback from the supervisor was positively related to job depression, job anxiety, and turnover 
intentions, and negatively related to job satisfaction. Frequency of positive feedback from the supervisor was negatively related to job depression and job anxiety and positively related to job satisfaction, but unrelated to turnover intentions. In the second step, we entered the mediator variables separately as predictors of well-being at work. Personal control over information turned out as significant negative predictor of job depression, job anxiety, and turnover intentions, and a significant positive predictor of job satisfaction. These results support Hypothesis 2a. Personal control over decisions also had a significant positive relationship to job satisfaction and a significant negative relationship to job depression, but was unrelated to job anxiety and turnover intentions. Thus, the data provided partial support for Hypothesis $2 \mathrm{~b}$. Helplessness was positively related to job depression, job anxiety, and turnover intentions, and negatively related to job satisfaction. These results fully support Hypothesis $2 \mathrm{c}$.

In a third set of models we tested our partial mediation hypotheses (Hypothesis 3a to 3c). We followed the Baron and Kenny (1986) procedure for mediation analysis and additionally used the Sobel (1982) Test to examine if the mediator carries the influence of the independent variable to the dependent variables. Support for the first requirement of the Baron and Kenny procedure was provided in finding the feedback environment to be related to the mediator variables (see test of Hypotheses 1a to 1c). Results testing the second and third steps are displayed in Table 4. In the first regression step, we entered the control variables. These steps are identical to the first steps in testing Hypotheses 2a to 2c (see Table 3, Step 1). In the second step, we entered feedback environment into the model. Feedback environment was a significant negative predictor of job depression and turnover intentions, and a significant positive predictor of job satisfaction.

To indicate a mediation of the relationship between feedback environment and well-being at work, each single mediator variable should predict the outcomes in the third step; additionally, the regression weight for feedback environment must be reduced in Step 3 compared to Step 2. Personal control over information and personal control over decisions were significant predictors for job depression and job satisfaction, while the respective regression weights of feedback environment were reduced but still significant, thus indicating partial mediation. Finally, helplessness significantly predicted job depression, job satisfaction, and turnover intentions. The simultaneous consideration of helplessness and feedback environment reduced the regression weights of feedback environment compared to Step 2, but the regression weight was still significant, thus indicating partial mediation. No mediation could be tested for job anxiety because the feedback environment did not predict job anxiety in the second step.

Results of the Sobel tests (1982) revealed that personal control over information indeed partially mediated the relationship between feedback 
TABLE 3

Regression results for Hypotheses 2a to 2c

\begin{tabular}{|c|c|c|c|c|c|c|c|c|}
\hline & \multicolumn{2}{|c|}{ Job depression } & \multicolumn{2}{|c|}{ Job anxiety } & \multicolumn{2}{|c|}{ Job satisfaction } & \multicolumn{2}{|c|}{ Turnover intentions } \\
\hline & $\beta$ & $t$ & $\beta$ & $t$ & $\beta$ & $t$ & $\beta$ & $t$ \\
\hline \multicolumn{9}{|l|}{ Step 1} \\
\hline Industry 1 & .04 & 0.72 & .03 & 0.60 & -.02 & -0.35 & .08 & 1.50 \\
\hline Industry 2 & -.06 & -1.07 & .12 & $2.20^{*}$ & .19 & $3.73^{* * *}$ & .08 & 1.44 \\
\hline Frequency negative feedback from supervisor & .30 & $5.96^{* * *}$ & .24 & $4.61 * * *$ & -.29 & $-5.93^{* * *}$ & .23 & $4.43^{* * *}$ \\
\hline \multirow[t]{2}{*}{ Frequency positive feedback from supervisor } & -.20 & $-3.88 * * *$ & -.16 & $-2.99^{* *}$ & .26 & $5.25 * * *$ & -.10 & -1.87 \\
\hline & \multicolumn{2}{|c|}{$R^{2}=.13$} & \multicolumn{2}{|c|}{$R^{2}=.09$} & \multicolumn{2}{|c|}{$R^{2}=.19$} & \multicolumn{2}{|c|}{$R^{2}=.07$} \\
\hline \multicolumn{9}{|l|}{ Step $2 a$} \\
\hline Industry 1 & .07 & 1.33 & .05 & 0.91 & -.06 & -1.30 & .10 & 1.77 \\
\hline Industry 2 & .01 & 0.21 & .15 & $2.79^{* *}$ & .09 & 1.85 & .11 & $1.99^{*}$ \\
\hline Frequency negative feedback from supervisor & .26 & $5.13^{* * *}$ & .22 & $4.09 * * *$ & -.23 & $-4.84^{* * *}$ & .21 & $3.95 * * *$ \\
\hline Frequency positive feedback from supervisor & -.14 & $-2.81^{* *}$ & -.13 & $-2.37^{*}$ & .18 & $3.80 * * *$ & -.07 & -1.32 \\
\hline \multirow[t]{2}{*}{ Personal control over information } & -.24 & $-4.49 * * *$ & -.13 & $-2.35^{*}$ & .35 & $6.97^{* * *}$ & -.12 & $-2.14^{*}$ \\
\hline & \multicolumn{2}{|c|}{$R^{2}=.18$} & \multicolumn{2}{|c|}{$R^{2}=.10$} & \multicolumn{2}{|c|}{$R^{2}=.29$} & \multicolumn{2}{|c|}{$\Delta R^{2}=.01^{*}$} \\
\hline \multicolumn{9}{|l|}{ Step $2 b$} \\
\hline Industry 1 & .06 & 1.12 & .04 & 0.72 & -.06 & -1.18 & .09 & 1.72 \\
\hline Industry 2 & -.03 & -0.54 & .13 & $2.34^{*}$ & .14 & $2.77^{* *}$ & .10 & 1.73 \\
\hline Frequency negative feedback from supervisor & .28 & $5.55^{* * *}$ & .23 & $4.42 * * *$ & -.25 & $-5.31^{* * *}$ & .22 & $4.15^{* * *}$ \\
\hline Frequency positive feedback from supervisor & -.19 & $-3.63 * * *$ & -.15 & $-2.89^{* *}$ & .23 & $4.94 * * *$ & -.09 & -1.70 \\
\hline \multirow[t]{2}{*}{ Personal control over decisions } & -.15 & $-2.97 * *$ & -.05 & -1.00 & .29 & $6.05 * * *$ & -.09 & -1.74 \\
\hline & \multicolumn{2}{|c|}{$\begin{array}{c}R^{2}=.15 \\
\Delta R^{2}=02^{* *}\end{array}$} & & $R^{2}=.09$ & \multicolumn{2}{|c|}{$R^{2}=.27$} & $R^{2}=.08$ & $\begin{array}{l}=.08 \\
=.01\end{array}$ \\
\hline
\end{tabular}


TABLE 3

(Continued)

\begin{tabular}{|c|c|c|c|c|c|c|c|c|}
\hline & \multicolumn{2}{|c|}{ Job depression } & \multicolumn{2}{|c|}{ Job anxiety } & \multicolumn{2}{|c|}{ Job satisfaction } & \multicolumn{2}{|c|}{ Turnover intentions } \\
\hline & $\beta$ & $t$ & $\beta$ & $t$ & $\beta$ & $t$ & $\beta$ & $t$ \\
\hline \multicolumn{9}{|l|}{ Step $2 \mathrm{c}$} \\
\hline Industry 1 & .05 & 1.15 & .04 & 0.90 & -.03 & -0.62 & .09 & 1.80 \\
\hline Industry 2 & -.04 & -0.98 & .13 & $2.67^{* *}$ & .18 & $3.90^{* * *}$ & .09 & 1.73 \\
\hline Frequency negative feedback from supervisor & .13 & $2.85^{* *}$ & .09 & 1.89 & -.16 & $-3.30^{* *}$ & .11 & $2.10^{*}$ \\
\hline Frequency positive feedback from supervisor & -.07 & -1.54 & -.05 & -0.98 & .16 & $3.43^{* *}$ & -.01 & -0.12 \\
\hline Helplessness & .54 & $11.52^{* * *}$ & .46 & $8.97^{* * * *}$ & -.42 & $-8.82 * * *$ & .39 & $7.29 * * *$ \\
\hline & \multicolumn{2}{|c|}{$\begin{array}{c}R^{2}=.38 \\
\Delta R^{2}=.25^{* * *}\end{array}$} & \multicolumn{2}{|c|}{$\begin{array}{c}R^{2}=.26 \\
\Delta R^{2}=.18^{* * *}\end{array}$} & \multicolumn{2}{|c|}{$\begin{array}{c}R^{2}=.34 \\
\Delta R^{2}=.15^{* * *}\end{array}$} & \multicolumn{2}{|c|}{$\begin{array}{c}R^{2}=.20 \\
\Delta R^{2}=.13^{* * *}\end{array}$} \\
\hline
\end{tabular}

Industry 1 was coded $1=$ hospitals, $0=$ other. Industry 2 was coded $1=\mathrm{R} \& \mathrm{D}, 0=$ others. ${ }^{*} p<.05, * * p<.01, * * * p<.001$. 
TABLE 4

Regression results for Hypotheses 3a to $3 \mathrm{c}$

\begin{tabular}{|c|c|c|c|c|c|c|c|c|}
\hline & \multicolumn{2}{|c|}{ Job depression } & \multicolumn{2}{|c|}{ Job anxiety } & \multicolumn{2}{|c|}{ Job satisfaction } & \multicolumn{2}{|c|}{ Turnover intentions } \\
\hline & $\beta$ & $t$ & $\beta$ & $t$ & $\beta$ & $t$ & $\beta$ & $t$ \\
\hline \multicolumn{9}{|l|}{ Step 2} \\
\hline Industry 1 & .05 & 1.03 & .02 & 0.45 & -.04 & -0.77 & .10 & 1.87 \\
\hline Industry 2 & -.03 & -0.51 & .13 & $2.38^{*}$ & .15 & $3.13^{* *}$ & .12 & $2.21^{*}$ \\
\hline Frequency negative feedback from supervisor & .22 & $4.01^{* * *}$ & .21 & $3.75^{* * *}$ & -.20 & $-3.74 * * *$ & .13 & $2.24^{*}$ \\
\hline Frequency positive feedback from supervisor & -.09 & -1.51 & -.12 & $-2.03^{*}$ & .13 & $2.42^{*}$ & .04 & 0.74 \\
\hline \multirow[t]{2}{*}{ Feedback environment } & -.25 & $-4.00^{* * *}$ & -.08 & -.1 .30 & .28 & $4.71^{* * *}$ & -.32 & $-5.02 * * *$ \\
\hline & \multicolumn{2}{|c|}{$\begin{array}{c}R^{2}=.17 \\
\Delta R^{2}=.04^{* * *}\end{array}$} & \multicolumn{2}{|c|}{$\begin{array}{c}R^{2}=.10 \\
\Delta R^{2}=.01\end{array}$} & \multicolumn{2}{|c|}{$\begin{array}{c}R^{2}=.24 \\
\Delta R^{2}=.05^{* * *}\end{array}$} & \multicolumn{2}{|c|}{$\begin{array}{c}R^{2}=.13 \\
\Delta R^{2}=.07^{* * *}\end{array}$} \\
\hline \multicolumn{9}{|l|}{ Step 3a } \\
\hline Industry 1 & .07 & 1.38 & .03 & 0.64 & -.06 & -1.37 & .10 & 1.94 \\
\hline Industry 2 & .02 & 0.38 & .16 & $2.83^{* *}$ & .08 & 1.70 & .13 & $2.32^{*}$ \\
\hline Frequency negative feedback from supervisor & .21 & $3.83^{* * *}$ & .21 & $3.62 * * *$ & -.18 & $-3.52^{* * *}$ & .12 & $2.19^{*}$ \\
\hline Frequency positive feedback from supervisor & -.07 & -1.29 & -.11 & -1.90 & .11 & $2.13^{*}$ & .05 & 0.78 \\
\hline Feedback environment & -.18 & $-2.87^{* *}$ & -.04 & -0.65 & .18 & $3.00^{* *}$ & -.31 & $-4.58^{* * *}$ \\
\hline \multirow[t]{2}{*}{ Personal control over information } & -.20 & $-3.47^{* *}$ & -.12 & $-2.03^{*}$ & .31 & 5.85 & -.04 & -0.73 \\
\hline & \multicolumn{2}{|c|}{$\begin{aligned} R^{2} & =.20 \\
\Delta R^{2} & =.03^{* *}\end{aligned}$} & \multicolumn{2}{|c|}{$\begin{array}{c}R^{2}=.11 \\
\Delta R^{2}=.01^{*}\end{array}$} & \multicolumn{2}{|c|}{$\begin{array}{c}R^{2}=.31 \\
\Delta R^{2}=.07^{* * *}\end{array}$} & \multicolumn{2}{|c|}{$\begin{array}{c}R^{2}=.14 \\
\Delta R^{2}=.00\end{array}$} \\
\hline
\end{tabular}


TABLE 4

(Continued)

\begin{tabular}{|c|c|c|c|c|c|c|c|c|}
\hline & \multicolumn{2}{|c|}{ Job depression } & \multicolumn{2}{|c|}{ Job anxiety } & \multicolumn{2}{|c|}{ Job satisfaction } & \multicolumn{2}{|c|}{ Turnover intentions } \\
\hline & $\beta$ & $t$ & $\beta$ & $t$ & $\beta$ & $t$ & $\beta$ & $t$ \\
\hline \multicolumn{9}{|l|}{ Step 3b } \\
\hline Industry 1 & .07 & 1.35 & .03 & 0.54 & -.07 & -1.51 & .11 & $2.01^{*}$ \\
\hline Industry 2 & -.01 & -0.09 & .14 & $2.48^{*}$ & .11 & $2.30^{*}$ & .13 & $2.37^{*}$ \\
\hline Frequency negative feedback from supervisor & .21 & $3.80^{* * *}$ & .21 & $3.66^{* * *}$ & -.17 & $-3.39 * *$ & .12 & $2.13^{*}$ \\
\hline Frequency positive feedback from supervisor & -.08 & -1.44 & -.12 & $-2.01^{*}$ & .13 & $2.36^{*}$ & .05 & 0.77 \\
\hline Feedback environment & -.23 & $-3.74^{* * *}$ & -.08 & -1.21 & .25 & $4.30^{* * *}$ & -.31 & $-4.87^{* * *}$ \\
\hline \multirow[t]{2}{*}{ Personal control over decisions } & -.13 & $-2.55^{*}$ & -.04 & -0.79 & .27 & $5.66^{* * *}$ & -.06 & -1.19 \\
\hline & \multicolumn{2}{|c|}{$\begin{array}{c}R^{2}=.19 \\
\Delta R^{2}=.02^{*}\end{array}$} & \multicolumn{2}{|c|}{$\begin{array}{c}R^{2}=.10 \\
\Delta R^{2}=.00\end{array}$} & \multicolumn{2}{|c|}{$\begin{array}{c}R^{2}=.31 \\
\Delta R^{2}=.07^{* * *}\end{array}$} & \multicolumn{2}{|c|}{$\begin{array}{c}R^{2}=.14 \\
\Delta R^{2}=.00\end{array}$} \\
\hline \multicolumn{9}{|l|}{ Step $3 c$} \\
\hline Industry 1 & .05 & 1.17 & .02 & 0.47 & -.04 & -0.82 & .10 & 1.97 \\
\hline Industry 2 & -.03 & -0.68 & .13 & $2.57^{*}$ & -.16 & $3.47^{* *}$ & .11 & $2.28^{*}$ \\
\hline Frequency negative feedback from supervisor & .10 & $2.06^{*}$ & .11 & $2.02^{*}$ & -.11 & $-2.15^{*}$ & .05 & 0.85 \\
\hline Frequency positive feedback from supervisor & -.03 & -0.50 & -.07 & -1.23 & .09 & 1.70 & .08 & 1.50 \\
\hline Feedback environment & -.11 & $-2.07^{*}$ & .04 & 0.61 & .18 & $3.19^{* *}$ & -.23 & $-3.72 * * *$ \\
\hline \multirow{2}{*}{ Helplessness } & .52 & $10.78^{* * *}$ & .46 & $8.85^{* * *}$ & -.39 & $-7.96^{* * *}$ & & $6.37^{* * *}$ \\
\hline & \multicolumn{2}{|c|}{$\begin{array}{c}R^{2}=.39 \\
\Delta R^{2}=.21^{* * *}\end{array}$} & \multicolumn{2}{|c|}{$\begin{array}{c}R^{2}=.27 \\
\Delta R^{2}=.17^{* * *}\end{array}$} & \multicolumn{2}{|c|}{$\begin{array}{c}R^{2}=.36 \\
\Delta R^{2}=.12^{* * *}\end{array}$} & \multicolumn{2}{|c|}{$\begin{array}{c}R^{2}=.23 \\
\Delta R^{2}=.09^{* * *}\end{array}$} \\
\hline
\end{tabular}

Industry 1 was coded $1=$ hospitals, $0=$ other. Industry 2 was coded $1=\mathrm{R} \& \mathrm{D}, 0=$ others. ${ }^{*} p<.05, * * p<.01,{ }^{* * *} p<.001$. 
environment and job depression, Sobel's $z=3.51, p<.001$, and job satisfaction, Sobel's $z=4.38, p<.001$. Personal control over decisions marginally mediated the relationship between feedback environment and job satisfaction, Sobel's $z=1.85, p<.10$, but not with job depression, Sobel's $z=1.62, p>.10$. Helplessness was a significant mediator in the relationships between feedback environment and job depression, Sobel's $z=4.01, p<$ .001 , job satisfaction, Sobel's $z=3.85, p<.001$, and turnover intentions, Sobel's $z=3.69, p<.001$. Therefore, Hypotheses $3 \mathrm{a}, 3 \mathrm{~b}$, and $3 \mathrm{c}$ received partial support from our data.

\section{DISCUSSION}

In this study we examined the mediating role of personal control over information and decisions and feelings of helplessness in the relationship between supervisor employee feedback environment and well-being at work. Replicating findings from other studies (Anseel \& Lievens, 2007; Rosen et al., 2006), we found feedback environment to be positively related to job satisfaction. Moreover, feedback environment was negatively related to job depression, turnover intentions, and feelings of helplessness, and was positively related to personal control over information and (marginally) decisions at work. Personal control over information, in turn, was negatively related to job depression, job anxiety, and turnover intentions, and positively related to job satisfaction, and helplessness was related to these outcome variables in the reverse direction. Personal control over decisions positively predicted job satisfaction and negatively predicted job depression. Finally, personal control over information partially mediated the relationships between feedback environment on the one hand and job depression and job satisfaction at the other hand. Personal control over decisions partially mediated the relationship between feedback environment and job satisfaction. Feelings of helplessness partially mediated the relationships of the feedback environment to job satisfaction, job depression, and turnover intentions. The relationship between the feedback environment and personal control over decisions was only marginally significant and therefore should be interpreted only with caution.

Taken together, our findings support and underline the relevance of the supervisor employee feedback environment for employees' well-being at work and reveal the different roles of personal control and feelings of helplessness as mediating variables of these relationships. Helplessness was found to be the strongest mediating variable out of the three variables used. This finding suggests that personal control at work might be one important resource in an advantageous feedback environment, but that the prevention of lack of control (helplessness) is even more important. Additionally, personal control over information was a stronger mediating variable than 
was personal control over decisions. Personal control over information might be a more proximal benefit from an advantageous feedback environment than personal control over decisions, which could be one explanation for these results. Furthermore, personal decision control is likely to be affected from a broader range of variables in the work context.

Until now only a few studies have used the Steelman et al. (2004) scale to assess feedback environment. Most of these studies have been conducted in the United States (one exception is Anseel \& Lievens, 2007). In our study, we applied the concept and instrument to German employees and were able to replicate earlier findings from Steelman et al. (2004), Rosen et al. (2006), and Anseel and Lievens (2007), particularly its relation to job satisfaction. Therefore, we can preliminarily conclude that feedback environment is an important aspect of the work context at least in Western countries. Additionally, in our study we surveyed regular employees from different industries, which enhances the possibility of generalizing the results. Moreover, our study adds to the existing literature on feedback environment by extending evidence for important outcomes of the feedback environment and introducing personal control and helplessness as mediating variables.

Controlling for the frequency of positive and negative feedback from the supervisor enabled us to examine the qualitative aspects of the feedback environment separated from the quantity of feedback received from the supervisor. Frequency of negative feedback from the supervisor had moderate negative relationships and frequency of positive feedback from the supervisor had moderate positive relationships to the feedback environment facets (see Table 1). Different interpretations of these results are plausible. First, employees in an advantageous feedback environment might experience feedback in a less negative and more positive way than employees in disadvantageous feedback environments. Second, positive feedback might be important for employees to evaluate their feedback environment as advantageous and negative feedback threatens this image. Findings showed that while the frequency of negative feedback from the supervisor was positively related to job depression, job anxiety, and turnover intentions, and negatively related to job satisfaction in the first step (see Table 3), these effects got smaller when entering the feedback environment variable in the second step (see Table 4). The same was true for the frequency of positive feedback from the supervisor with its relationship to job depression, job anxiety, and job satisfaction becoming smaller after entering the feedback environment variable. Feedback environment does not have a significant relationship to job anxiety when frequency of feedback is controlled, but does have a significant effect when it is not. Together, these results indicate that both quality and quantity of the feedback environment are important for well-being at work. Therefore, it might be worthwhile to examine qualitative and quantitative aspects of the 
feedback environment as well as possible interactions separately before they are integrated into one construct.

Of course, our study has some limitations. One apparent limitation is the cross-sectional design with self-report data which does not allow for drawing causal conclusions. It might well be that, for example, job satisfaction also influences the feedback environment, either because more satisfied employees participate in creating more advantageous feedback environments, or because more satisfied employees see their work context in a more positive light. For example, the study of van Dierendonck et al. (2004) has shown that leadership behaviours including feedback delivery were connected to employee well-being in a feedback loop that can also be reasonably assumed for the relationship between the supervisor feedback environment and wellbeing.

\section{Further research and practical implications}

All in all we found a meaningful pattern of results concerning the relationships between supervisor employee feedback environment, personal control, helplessness, and well-being at work. These findings promise to bring new insights into the relationships between feedback and important work-related outcomes. More research is required to learn about the development and stability of the feedback environment. Probably the most fruitful next steps in theory building would be attempts to integrate research on the feedback environment with the feedback-seeking (e.g., Ashford \& Cummings, 1983; Ashford, Blatt, \& VandeWalle, 2003) and feedbackintervention literatures (e.g., Kluger \& DeNisi, 1996), thus developing an integrated theory about feedback in the work context. A systematic identification and examination of moderators in the relationships between the feedback environment and important work-related outcomes should be encouraged, based on the moderators identified in studies about feedback seeking (e.g., Renn \& Fedor, 1990) and in testing the feedback intervention theory (Kluger \& DeNisi, 1996).

In our study, we concentrated on the supervisor employee feedback environment. Of course, more research is needed about the co-worker part of the feedback environment and, as mentioned earlier, the interplay between these two feedback environment components.

Personal control is a construct that is central in theory and research about psychological empowerment (e.g., Menon, 1991; Spreitzer, 1995; Thomas \& Velthouse, 1990). In a meaningful next step it would be interesting to examine the relationships between feedback environment and the four psychological experiences of empowerment, namely meaning, competence, self-determination, and impact (Spreitzer, 1995, 1996; Thomas \& Velthouse, 1990 ) in order to find out if high quality feedback environment expresses 
itself in psychological experiences of empowerment. This research might enhance our understanding of feedback environment's effects on important work-related outcomes as psychological empowerment has been found to prevent employees from ill health (Hochwälder, \& Brucefors, 2005), enhance job satisfaction (Laschinger, Finegan, Shamian, \& Wilk, 2004), and influence the propensity to leave (Koberg, Boss, Senjem, \& Goodman, 1999).

In our study, feedback environment was negatively related to job depression and turnover intentions and positively related to job satisfaction. These findings underline the importance of the feedback quality as well as the importance of a favourable context in which feedback information is delivered and available for employees. These results, together with the results from Norris-Watts and Levy (2004) on organizational citizenship behaviour and Rosen et al. (2006) on task performance, strengthen the argument that supervisors need to be trained thoroughly in feedback delivery skills in order to enhance their employees' motivation, affect, and performance. Additionally, leadership trainings that provide skills for enhancing the feedback environment might also have positive effects on the co-worker part of the feedback environment. The trained supervisor could serve as role model for constructive feedback practices at the work-place.

Taken together, our results give support to the assumption that creating an advantageous feedback environment might be a valuable resource for employees that has beneficial effects on feelings of control and well-being at work. Making aware the importance of feedback and constructive dealing with feedback could therefore contribute to both the employees' and organization's well-being.

\section{REFERENCES}

Anseel, F., \& Lievens, F. (2007). The long-term impact of the feedback environment on job satisfaction: A field study in a Belgian context. Applied Psychology: An International Review, $56,254-266$.

Ashford, S. J. (1986). Feedback-seeking in individual adaptation: A resource perspective. Academy of Management Journal, 29, 465-487.

Ashford, S. J., Blatt, R., \& VandeWalle, D. (2003). Reflections on the looking glass: A review of research on feedback-seeking behavior in organizations. Journal of Management, 29, 773-799.

Ashford, S. J., \& Cummings, L. L. (1983). Feedback as an individual resource: Personal strategies of creating information. Organizational Behavior and Human Performance, 32, 370-398.

Ashforth, B. E. (1989). The experience of powerlessness in organizations. Organizational Behavior and Human Decision Processes, 43, 207-242.

Ashforth, B. E., \& Saks, A. M. (2000). Personal control in organizations: A longitudinal investigation with newcomers. Human Relations, 53, 311-339.

Baron, R. M., \& Kenny, D. A. (1986). The moderator-mediator variable distinction in social psychological research: Conceptual, strategic and statistical considerations. Journal of Personality and Social Psychology, 51, 1173-1182. 
Becker, T. E., \& Klimoski, R. J. (1989). A field study of the relationship between the organizational feedback environment and performance. Personnel Psychology, 42, 343-358.

Breitkopf, L. (1985). Die Hilflosigkeitsskala [The helplessness scale]. Diagnostica, 31, 221-233.

Fedor, D. B. (1991). Recipient responses to performance feedback: A proposed model and its implications. Research in Personnel and Human Resources Management, 9, 73-120.

George, J. M., \& Jones, G. R. (1996). The experience of work and turnover intentions: Interactive effects of value attainment, job satisfaction, and positive mood. Journal of Applied Psychology, 81, 318-325.

Greenberger, D. B., \& Strasser, S. (1986). Development and application of a model of personal control in organizations. Academy of Management Review, 11, 164-177.

Greller, M. M., \& Herold, D. M. (1975). Sources of feedback: A preliminary investigation. Organizational Behavior and Human Performance, 13, 244-256.

Griffeth, R. W., Hom, P.W., \& Gaertner, S. (2000). A meta-analysis of antecedents and correlates of employee turnover: Update, moderator tests, and research implications for the next millennium. Journal of Management, 26, 463-488.

Hackman, J. R., \& Oldham, G. R. (1976). Motivation through the design of work: Test of a theory. Organizational Behavior and Human Performance, 16, 250-279.

Herold, D. M., \& Parsons, C. K. (1985). Assessing the feedback environment in work organizations: Development of the job feedback survey. Journal of Applied Psychology, 70, $290-305$.

Hochwälder, J., \& Brucefors, A. B. (2005). Psychological empowerment at the workplace as a predictor of ill health. Personality and Individual Differences, 39, 1237-1248.

Ilgen, D. R., Fisher, C. D., \& Taylor, M. S. (1979). Consequences of individual feedback on behavior in organizations. Journal of Applied Psychology, 64, 349-371.

Kinicki, A. J., Prussia, G. E., Wu, B. J., \& McKee-Ryan, F. M. (2004). A covariance structure analysis of employees' response to performance feedback. Journal of Applied Psychology, 89, $1057-1069$.

Kluger, A. N., \& DeNisi, A. (1996). The effects of feedback interventions on performance: A historical review, a meta-analysis, and a preliminary feedback intervention theory. Psychological Bulletin, 119, 254-284.

Koberg, C. S., Boss, R. W., Senjem, J. C., \& Goodman, E. A. (1999). Antecedents and outcomes of empowerment. Group and Organization Management, 24, 71-91.

Kunin, T. (1955). The construction of a new type of attitude measure. Personnel Psychology, 8 , $65-78$.

Laschinger, H. K. S., Finegan, J. E., Shamian, J., \& Wilk, P. (2004). A longitudinal analysis of the impact of workplace empowerment on work satisfaction. Journal of Organizational Behavior, 25, 527-545.

Levy, P. E., \& Williams, J. R. (2004). The social context of performance appraisal: A review and framework for the future. Journat of Management, 30, 881-905.

Menon, S. T. (1991). Employee empowerment: An integrative psychological approach. Applied Psychology: An International Review, 50, 153-180.

Norris-Watts, C., \& Levy, P. E. (2004). The mediating role of affective commitment in the relation of the feedback environment to work outcomes. Journal of Vocational Behavior, 65, 351-365.

Peterson, C. (1999). Personal control and well-being. In D. Kahneman, E. Diener, \& N. Schwarz (Eds.), Well-being: The foundations of hedonic psychology (pp. 288-301). New York: Russell Sage Foundation.

Peterson, C., Maier, S. F., \& Seligman, M. E. P. (1993). Learned helplessness: A theory for the age of personal control. New York: Oxford University Press.

Renn, R. W., \& Fedor, D. B. (2001). Development and field test of a feedback seeking, selfefficacy, and goal setting model of work performance. Journal of Management, 27, 563-583. 
Rosen, C. C., Levy, P. E., \& Hall, R. J. (2006). Placing perceptions of polities in the context of the feedback environment, employee attitudes, and job performance. Journal of Applied Psychology, 91, 211-220.

Rutkowski, K. A., \& Steelman, L. A. (2005). Testing a path model for antecedents of accountability. Journal of Management Development, 24, 473-486.

Seligman, M. E. P. (1975). Helplessness: On depression, development, and death. San Francisco, CA: W.H Freeman.

Skinner, E. A. (1996). A guide to constructs of control. Journal of Personality and Sociat Psychology, 71, 549-570.

Sobel, M. E. (1982). Asymptotic confidence intervals for indirect effects in structural equation models. In S. Leinhardt (Ed.), Sociological methodology (pp. 290-312). Washington, DC: American Sociological Association.

Spector, P. E. (2002). Employee control and occupational stress. Current Directions in Psychological Science, 11, 133-136.

Spreitzer, G. M. (1995). Psychological empowerment in the workplace: Dimensions, measurement, and validation. Academy of Management Journal, 38, 1442-1465.

Spreitzer, G. M. (1996). Social structural characteristics of psychological empowerment. Academy of Management Journal, 39, 483-504.

Steelman, L. A., Levy, P. E., \& Snell, A. F. (2004). The feedback environment scale: Construct definition, measurement, and validation. Educational and Psychological Measurement, 64, $165-184$.

Thomas, K. W., \& Velthouse, B. A. (1990). Cognitive elements of empowerment: An "interpretive" model of intrinsic task motivation. Academy of Management Review, 15, 666681.

Van den Berg, P. T., \& Feij, J. A. (2003). Complex relationships among personality traits, job characteristics, and work behaviors. International Journal of Selection and Assessment, 11, 326-341.

Van Dierendonck, D., Haynes, C., Borril, C., \& Stride, C. (2004). Leadership behavior and subordinate well-being. Journal of Occupational Health Psychology, 9, 165-175.

Walsh, J. P., Ashford, S. J., \& Hill, T. E. (1985). Feedback obstruction: The influence of the information environment on employee turnover intentions. Human Relations, 38, 23-46.

Wanous, J. P., Reichers, A. E., \& Hudy, M. J. (1997). Overall job satisfaction: How good are single-item measures? Journal of Applied Psychology, 82, 247-252.

Warr, P. (1990). The measurement of well-being and other aspects of mental health. Journal of Occupational Psychology, 63, 193-210.

Warr, P. (1999). Well-being at the workplace. In D. Kahneman, E. Diener, \& N. Schwarz (Eds.), Well-being: The foundations of hedonic psychology (pp. 392-412). New York: Russell Sage Foundation.

Warr, P. (2007). Work, happiness, and unhappiness. Mahwah, NJ: Lawrence Erlbaum Associates, Inc. 